\title{
A maintenance system model for optimal reconfigurable vibrating screen management
}

\author{
O. A. Makinde ${ }^{1}$ K. Mpofu ${ }^{1}$ B. I. Ramatsetse ${ }^{1} \cdot$ M. K. Adeyeri $^{2}$. \\ S. P. Ayodeji ${ }^{2}$
}

Received: 8 March 2017 / Accepted: 4 October 2017/Published online: 16 October 2017

(C) The Author(s) 2017. This article is an open access publication

\begin{abstract}
The reconfigurable vibrating screen (RVS) machine is an innovative beneficiation machine designed for screening different mineral particles of varying sizes and volumes required by the customers' through the geometric transformation of its screen structure. The successful RVS machine upkeep requires its continuous, availability, reliability and maintainability. The RVS machine downtime, which could erupt from its breakdown and repair, must also be reduced to the barest minimum. This means, there is a need to design and develop a maintenance system model that could be used to effectively maintain the RVS machine when utilized in surface and underground mines. In view of this, this paper aims to develop a maintenance system model that could be used to effectively maintain the RVS machine when used in surface and underground mines. The maintenance system model unfolds the predictive (i.e. diagnosis and prognosis) algorithms, the e-maintenance strategic tools as well as the dynamic maintenance strategic algorithms required to
\end{abstract}

O. A. Makinde

olasumbomakinde@gmail.com

K. Mpofu

mpofuk@tut.ac.za

B. I. Ramatsetse

ramatsetsebi@tut.ac.za

M. K. Adeyeri

adeyerimichaeltut@gmail.com

S. P. Ayodeji

ayodejisesan@yahoo.comm

1 Department of Industrial Engineering, Tshwane University of Technology (TUT), Pretoria, South Africa

2 Department of Mechanical Engineering, Federal University of Technology, Akure (FUTA), Akure, Nigeria effectively maintain the RVS machine. Four different case studies were presented in this paper to illustrate the applicability of this maintenance system model in maintaining and managing the RVS machine when utilized in the mining industries.

Keywords Reconfigurable vibrating screen - Reliability · Dynamic maintenance $\cdot$ Maintainability $\cdot$ LABVIEW $^{\circledR}$

\section{Introduction}

Fluctuation in mineral concentrates demand and vacillation in productivity rates of beneficiation machines owing to machine breakdown and maintenance (which result into downtime) has called for the design of a RVS machine, capable of amassing the beneficiation productivity rates of this machine in meeting customers demand as well as marking-up the production that might be lost during its breakdown and repair operations (Makinde et al. 2015, 2016a). According to Ramatsetse (2014), a RVS machine is a customized-transformable screening machine designed to separate mineral particles into different sizes (e.g. $10 \mu \mathrm{m}, 10$ and $30 \mathrm{~mm}$ mineral particle sizes) and volumes (i.e. screening of 30,45 or 60 tons/h based on customers demand) through the geometric transformation of its structure (Fig. 1).

This machine solution (Fig. 2) has the potential of meeting the stochastic and dynamic customer demands in a cost effective manner as well as recovering the production loss that emanates during the maintenance of the machine.

In order to ensure optimal functionality of this machine when used in surface and underground mines, there is a need to develop a maintenance system capable of: (1) ascertaining the exact time of failure of the different 
Fig. 1 Different RVS machine at configuration capacities of $2500 \mathrm{~mm} \times 1500 \mathrm{~mm}$, $3500 \mathrm{~mm} \times 2000 \mathrm{~mm}$ and $4700 \mathrm{~mm} \times 2500 \mathrm{~mm}$

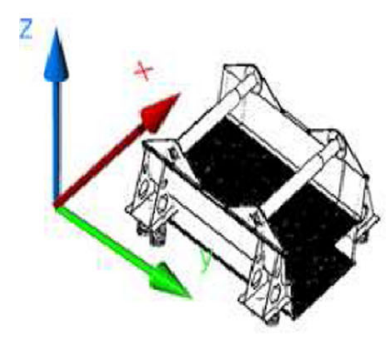

(c) $1^{\text {st }}$ Configuration

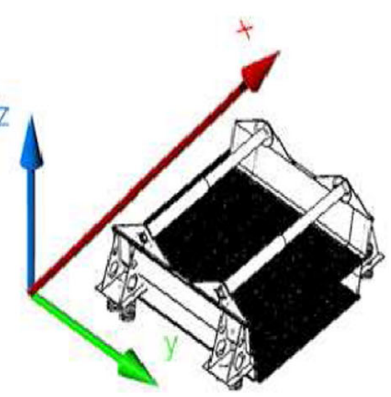

(b) $2^{\text {nd }}$ Configuration

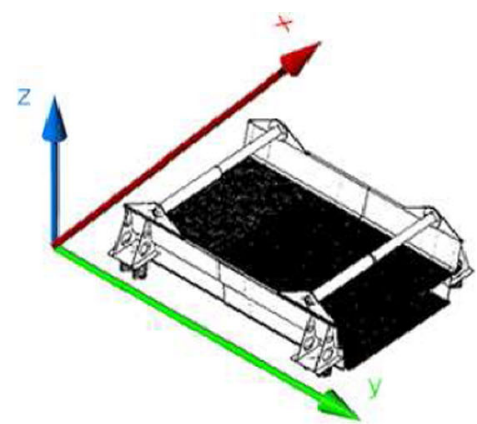

(a) $3^{\text {rd }}$ Configuration

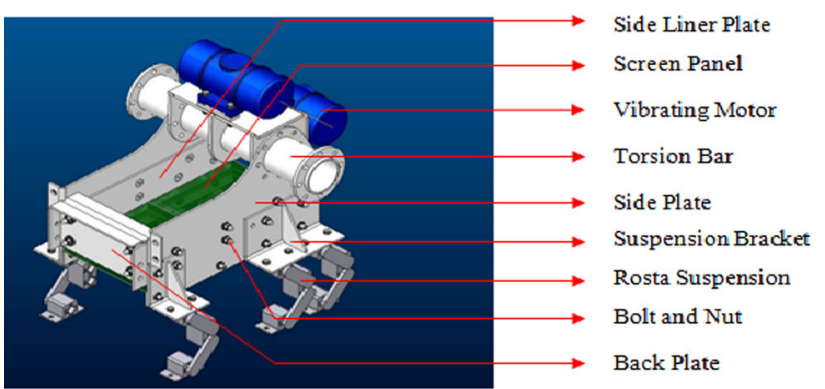

Fig. 2 RVS machine

subsystems of this machine, (2) predicting when the machine subsystems will fail for effective RVS machine subsystem spare part management, and (3) ascertaining the time to configure the RVS machine to a new machine configuration in meeting new customers demand or recovering production loss that could emanate during the maintenance of this machine. To solve this problem, different maintenance management systems serves as potential solutions to be adopted in optimally maintaining the RVS machine when utilized in both surface and underground mines. These includes corrective maintenance i.e. "break and repair" maintenance techniques (Salonen and Deleryd 2011); a preventive maintenance system i.e. "fix it before it fail" maintenance strategy (Sheu and Kuo 2006), and an opportunistic maintenance system i.e. "fix if you are opportune to identify the fault" maintenance strategy (Cui and $\mathrm{Li}$ 2006). Other systems, on the one hand, include a predictive maintenance system i.e. "systematically guess when a subsystem will fail" maintenance strategy (Shrotri and Khandagale 2012) and a total productive maintenance (TPM) system i.e. "investigate, find and proffer solutions to the cause of machine failure and production loss" maintenance strategy (Rajput and Jayaswal 2012). On the other hand, it includes a dynamic maintenance system i.e. "customer-driven" maintenance oriented strategy (Adeyeri and Kareem 2012) and an e-maintenance system i.e. "an electronic-oriented diagnosis, prognosis, maintenance planning and inventory" strategy (Muller et al. 2008). However, there is a need to ascertain which of these aforementioned strategies will be suitable in maintaining the RVS machine and as well as to map out the strategic procedures or processes required to achieve effective maintenance of the RVS machine. In view of this, the current paper proposes a maintenance management system model that could be adopted to maintain the RVS machine when utilized in the mining industries. To this effect, the first section of this paper extensively reviews the different maintenance management systems used for maintaining the different machines used in manufacturing industries. The purpose of this will be to ascertain the best maintenance practices suitable for managing the RVS machine when used in surface and underground mines. The second section presents a holistic assessment of the RVS machine using an IDEF0 diagram, with a view to ascertain the necessary subsystems which need to be maintained on the machine. The last section presents a suitable maintenance management system model that could be adopted to effectively maintain the RVS machine.

\section{State of the art in machine maintenance management system}

Machine maintenance is vital for optimal functionality, reliability and maintainability of different subsystems of a machine. According to Wan et al. (2014), maintenance is a sequence of operations that is carried out on an item or a machine. Through this process, specific tools, technologies and procedures are used to keep a system in its functional state or transform its current state into a new state which conforms to the machine system manufacturer's designed performance. According to Hashemian (2011), different maintenance strategies systems have evolved over the past couple of years. These embrace the corrective maintenance (CM) system, preventive maintenance (PM) system, opportunistic maintenance (OM) system, predictive maintenance (PrM) system, total productive maintenance (TPM) system, dynamic maintenance (DM) system and e-maintenance (e-M). A substantial number of machine maintenance solutions have been developed by different 
researchers using these maintenance strategies. For example, Kenne et al. (2003) formulated a computational algorithm required to solve a corrective maintenance problem. This helped to control the production rates in a manufacturing system made up of several identical machines during the machine breakdown and maintenance process. It also assisted in minimizing the cost of surplus and repair activities. Iyoob et al. (2003) highlighted the significance of the corrective models such as renewal, minimal, Kijima I, Kijima II and quasi renewal models e.t.c. in determining the availability, reliability and functionality of machines used in different manufacturing industries.

Carlo et al. (2004) developed a Bayesian model that was used to determine the right corrective measure required to increase the shelf life of different machines when aging sets in. Quitana et al. (2009) further developed a rule-based corrective maintenance system that could be used in a dynamic manufacturing environment without adding reconfiguration costs to the maintenance cost of the machines used in this environment. Adolfsson and Dahlstrom (2011) developed a model that could be used to evaluate the efficiency of the maintenance carried out on various subsystems of a machine. The model was tested using machine performance data, observed information and information obtained from machine experts. Wang et al. (2014) developed a corrective maintenance scheme, which unfolds an extended failure mode effect and critical analysis (FMECA) as well as failure propagation graphical (FPG) synthesis and diagnosis in determining when to replace the different subsystems of a machine. In driving the use of the PM strategy for the maintenance of machines, (Oyedepo and Fagbenle 2011) assessed the potential of implementing preventive maintenance strategies in order to boost the performance of the Egbin $1320 \mathrm{MW}$ thermal power plant in Nigeria. Afefy (2012) developed a computer-aided preventive maintenance framework that could maintain a machine. Osman et al. (2015) also developed a computerized preventive maintenance software tool to implement a risk-oriented prioritization of machines needed to be maintained in different Haematology departments of hospitals.

Ireland and Dale (2001) also drove the use of the TPM strategy for the maintenance of machines used in manufacturing industries. This was achieved through the utilization of the TPM strategy in three companies facing business difficulties using the Nakajima's seven steps of achieving autonomous maintenance. Singh et al. (2013) further implemented all the seven pillars of TPM maintenance strategy to improve the overall equipment effectiveness (OEE) of CNC machines of different capacities used in a machine workshop. The seven pillars, Lean concepts of Just-In-Time and Kanban were implemented in a small scale polymer manufacturing industry with a view to increase the productivity rate and quality of work done in this environment (Muruganantham et al. 2014).

In expediting the use of OM maintenance strategy for the maintenance of machines used in manufacturing industries, Mohamed-Salah et al. (1999) developed an opportunistic maintenance simulation model that could be used to maintain a production line consisting of $\mathrm{k}$ nonidentical processors (which does not exhibit intermediary stocks). Samhouri et al. (2011) developed an intelligent opportunistic maintenance algorithm that could be used to effectively repair or replace complex machines in a cost effective manner. In the same vein, Tambe and Kulkarni (2013) developed an opportunistic maintenance decision model that could be used to ascertain when to replace or repair different subsystems of a die casting machine using genetic algorithms. In motivating the use of a PrM strategy for the maintenance of machines in manufacturing industries, Li et al. (2005) developed a web agent-based predictive maintenance system model that could be used for diagnosing and prognosing when to repair or replace different subsystems of a machine. Gross et al. (2005) developed a machine learning (ML) system known as ranker for open-auto maintenance scheduling (ROAMS) that could be used to rank the failure-susceptibility of about 1000 energy distribution feeder cables that supply electricity to different locations in New York City. Munirathinam and Ramadoss (2016), using WEKA tool and R languages, constructed a predictive model that could be used to detect when any subsystem of a machine used in semi-conductor industries will fail or become faulty during the wafer fabrication process. Furthermore, in driving the use of a DM strategy for the maintenance of machines used in manufacturing industries, Bouillaut et al. (2008) developed a dynamic maintenance model that could be used to ascertain rail degradation rates and the behavior of various actors involved in machine defect detection. They applied Bayesian Networks, in order to determine the optimal maintenance parameters for effective functionality of rails. Also, Adeyeri et al. (2011), proposed a dynamic maintenance model that could be used to ascertain when and at what point in time a maintenance strategy or maintenance technique mix needed to be used. The purpose of this was to reduce material wastage subsequent to poor machine performance and machine break down, which results in machine downtime. Also, in expediting the use of an e-M strategy for the maintenance of machines used in manufacturing industries, Lee et al. (2006) proposed the relevant diagnostic and prognostic tools required for up-to-date assessment and prediction of the performance of machines used in manufacturing industries. Haider and Koronios (2006) presented a holistic scheme needed to carry out effective machine diagnosis using radio frequency identification (RFID) technology. This enabled proactive 
determination of the maintenance requirements of different subsystems of a machine wirelessly without human intervention. Juricic et al. (2013) also proposed a low cost online diagnostic and prognostic system that could be used to effectively maintain a machine, when the operating conditions are not fully accessible, measurable and incomplete.

Makinde et al. (2016b) also discussed an IEAPMS (intelligent e-assessment and prognosis management system) e-maintenance framework and an e-machine temperature monitoring algorithms that could be used in optimally maintaining and preserving the functionality of different machines used in a manufacturing industry. Adeyeri et al. (2016) investigated the potential of using temperature and vibration models to monitor the performance of conventional machines, in which their functionalities are hampered by abnormal changes in temperature and vibration values. The study established that increment in the operating temperature and vibration of different subsystems of a machine results in a rapid decline in machine reliability. Mortazavi et al. (2017) evaluated the mean time between failure (MTBF) of a 2-out-of-3 repairable redundant system using a combination of the alpha-factor and capacity flow models in order to appraise the common causes of machine failures. Based on this holistic assessment of different maintenance strategies and systems, rhetorical question such as "which maintenance strategy(ies) are required in optimally maintaining the RVS machine when used in the mining industries?" need to be answered. To answer this question, a deep understanding of which different components need to be maintained on the RVS machine and other maintenance requirements required for its optimal functionality must be carefully investigated.

\section{Reconfigurable vibrating screen}

In order for the RVS machine, to be utilized in both surface and underground mines, optimal stability and functioning of different subsystems of the machine will be required (such as screen panels, vibrating motor, screen deck frame, springs, bolts, side plates, torsion bar, clamps, hydraulic cylinders and torsion bar brackets e.t.c.). These are highlighted in the RVS machine functionality IDEF0 (ICAM definition for function modeling, where 'ICAM' is an acronym for integrated computer aided manufacturing) diagram depicted in Fig. 3. These subsystems in the IDEF0 diagram ensures the effective screening of mineral particles at the different configurations that the machine is adjusted to, in meeting sporadic customers demand. The RVS machine functionality IDEF0 diagram highlights the functional transition states of the RVS machine vis-à-vis the activities or actions that must be carried out by the maintenance managers of the machine for its effectively maintenance.

To this effect, a hybrid maintenance system which mixes the predictive (i.e. diagnostic and prognostic approaches), e-maintenance and dynamic maintenance management strategies will be suitable for optimally maintaining the RVS machine. The next section of this paper therefore presents a maintenance management system framework for the RVS machine. This unfolds the maintenance strategies that could be used to ensure just-intime, effective, safe and customer-demand driven maintenance of the RVS machine when utilized in both surface and underground mining environments.

\section{Maintenance system framework for effective RVS machine management}

The maintenance management system framework which highlights the maintenance strategies and tools and is required to effectively maintain the RVS machine when used in surface and underground mines is depicted in Fig. 4. In this figure, the major maintenance strategies required in maintaining the RVS machine include the predictive, e-maintenance and dynamic maintenance strategic systems.

\section{RVS machine predictive maintenance system}

The predictive maintenance system for the RVS machine maintenance process can be classified into diagnosing and prognosing systems.

\section{RVS machine diagnosis system model}

A machine diagnosis system entails developing a system that can be used to monitor in real-time and detect faults present in different subsystems of a machine. This uses some intelligent rule-based machine fault detection algorithms developed by experts of such machine systems. Given this, the RVS machine diagnosis system involves the utilization of sensors such as thermocouples, strain gauges, accelerometers, oil level sensors and smart bolt wireless sensors to measure in real-time the temperature at which the vibrating motor powering the RVS machine is running. The sensors must measure the real-time stress and deformation that the RVS subsystems such as screen panels, screen deck frame, side plates, side liner plates, back plates, torsion bar, torsion bar brackets and M-16 bolts e.t.c. of the machine are subjected to. They must ascertain real-time vibrations generated by the vibrating motor. They must monitor the lubricating oil level of the oil compartment of vibrating motor. The oil is responsible for the lubrication of shaft and bearing powering the vibrating 


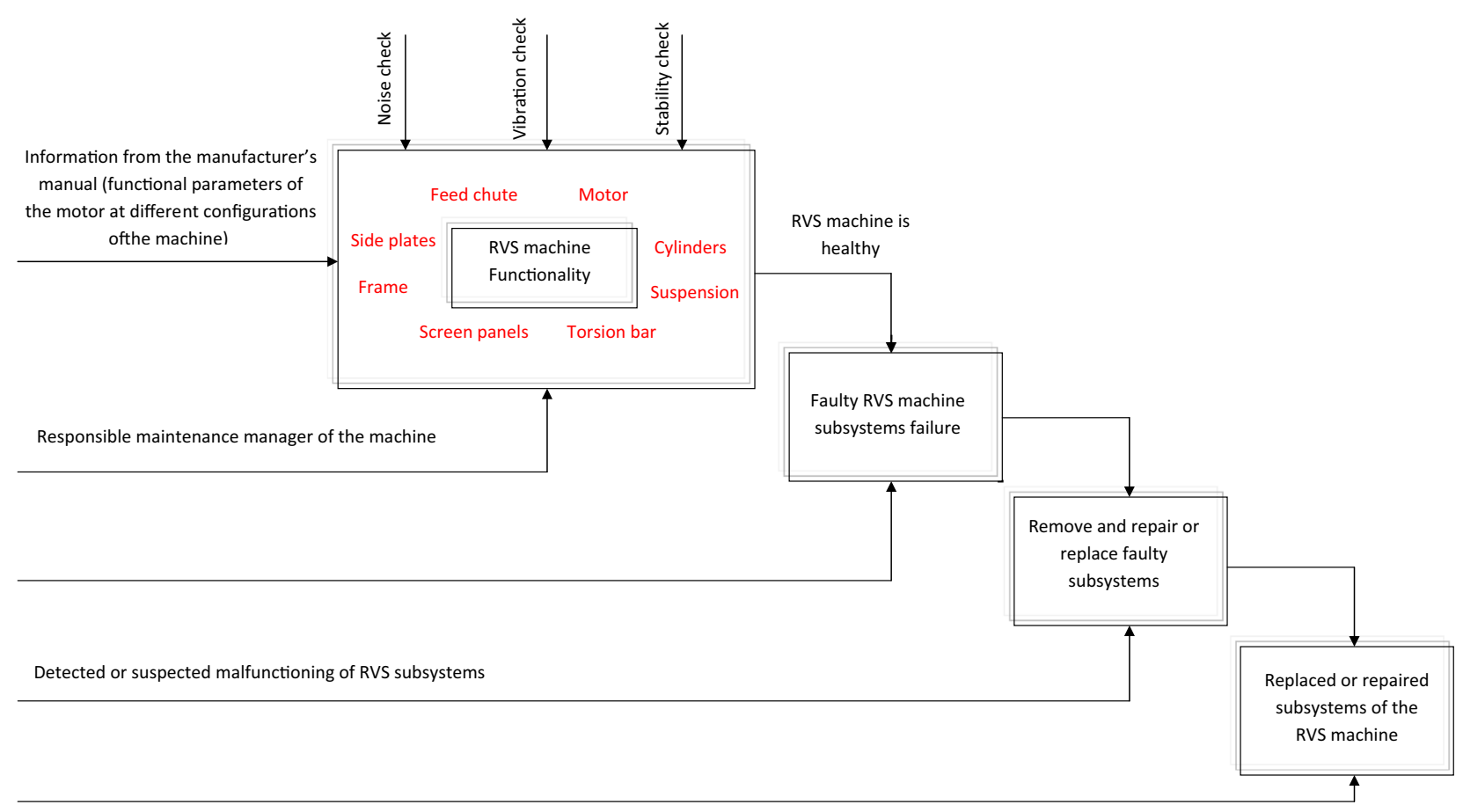

Fig. 3 RVS machine functionality IDEF0 diagram

motor. The measured values obtained from these sensors are then compared with the rule-based RVS subsystems performance algorithms developed by RVS machine manufacturer. This will alert the users and maintenance managers of this machine when over-heating and knocking of the vibrating motor occurs and when deformation, degradation and wear of the aforementioned subsystems of the RVS machine sets in. It will reveal when the shaft, bearing and half-circular spinning discs (responsible for the machine vibration) inside the vibrating motor deform, break and wear.

The real-time machine performance monitoring system to be used for the RVS machine diagnosis is the national instrument real-time system. This utilizes the LABVIEW $^{\circledR}$ software which codes the rule-based RVS machine subsystems performance algorithms. The system also generates a user interface or front panel for RVS machine maintenance managers and compatible sensor data acquisition modules. This interface with the afore discussed sensors was used to analyze the real-time RVS machine subsystems performance data using statistical tools such as the fast fourier transform (FFT), Morlet wavelet filtering (MWF) and autoregressive algorithms and a real-time Compat RIO module. The RVS machine subsystems conditions are presented in real-time to the RVS machine users on the user interface. This is achieved by comparing the analysed measured results obtained from the data acquisition modules against the rule-based RVS machine maintenance algorithms coded on the block diagram of the LABVIEW $^{\circledR}$ software. A rule-based machine maintenance algorithm is depicted in Table 1. The algorithm is formulated by ascertaining the maximum or critical operating conditions of RVS machine subsystems at which these subsystems will fail through a dynamic simulation of the machine configured to beneficiate run-off iron ore and coal mineral particles using ANSYS ${ }^{\circledR}$ software. This algorithm ascertains the RVS machine subsystem functional conditions in real-time, when the RVS machine is configured to a production capacity of $600 \mathrm{~mm}$ by $1200 \mathrm{~mm}$ for screening coal particles of bulk density $960 \mathrm{~kg} / \mathrm{m}^{3}$ and iron ore particles of bulk density $2595 \mathrm{~kg} / \mathrm{m}^{3}$; as obtained by the RVS machine maintainability designers.

Also, a typical user interface (front panel) and block diagram that was coded and developed for real-time monitoring of the temperature of the vibrating motor of the RVS machine is depicted in Figs. 5 and 6. The relevant functions palette and diagnostic statistical tools used to develop the front panel and the block diagram of this RVS machine diagnosis system were obtained from the module library of LABVIEW ${ }^{\circledR}$ software. 


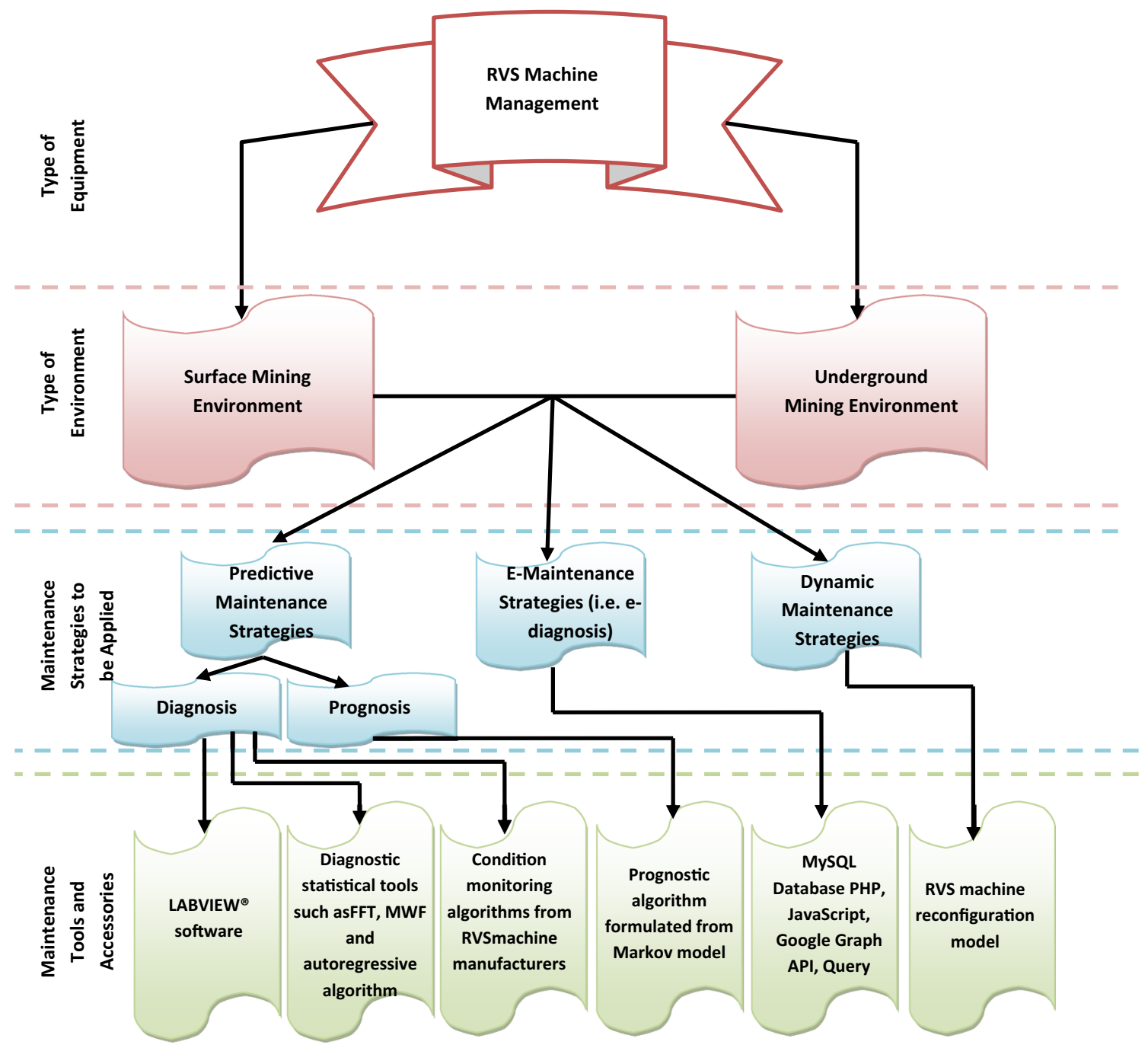

Fig. 4 Maintenance management system framework for effective RVS machine management

The major steps required for developing the aforementioned user interface and block diagram responsible for the vibrating motor monitoring on the RVS machine is highlighted as follows.

i. Open the LABVIEW software by double clicking on the LABVIEW icon on your desktop.

ii. Double click the blank project to open a new virtual instrument "VI" front panel.

iii. Open the functions palette on the front panel of the VI and drag three numeric controls.

iv. Rename these numeric controls as current temperature, maximum temperature and minimum temperature by double clicking their default labels and editing them.

v. Drag one string indicator from the functions palette on the front panel of the VI and rename it as "warning text". vi. Drag one boolean indicator from the functions palette on the front panel of the VI and rename it as "warning".

vii. Open the block diagram.

viii. Drag the thermometer sub-VI into the block diagram. The thermometer has been coded and developed to acquire and analyze the raw realtime temperature data from the thermocouple connected to the RVS machine using statistical tools such as FFT, MWF and autoregressive algorithm. Next, drag the bundle by name function into the block diagram. This bundles the real-time readings of the current, maximum and minimum temperature for comparison in order to ascertain the current condition of the machine.

ix. Wire the input and output nodes of all the functions that appear on the block diagram. 
Table 1 RVS machine subsystems rule-based condition monitoring algorithm

\begin{tabular}{|c|c|}
\hline Rule & Triggering Context \\
\hline $\begin{array}{l}\sigma_{\text {torsion bar }}<21.2 \mathrm{MPa}, \sigma_{\text {side plate }}<7.5 \mathrm{MPa}, \sigma_{\text {rosta suspension }}<4.3 \mathrm{MPa} \text {, } \\
\sigma_{\text {back plate }}<15.4 \mathrm{MPa} \text { and } \sigma_{\text {screen deck frame }}<15.3 \mathrm{MPa} \text { when RVS machine is used for } \\
\text { screening iron ore particles }\end{array}$ & $\begin{array}{l}\text { No warning-RVS subsystems are in healthy } \\
\text { conditions }\end{array}$ \\
\hline $\begin{array}{l}\sigma_{\text {torsion bar }} \geq 21.2 \mathrm{MPa}, \sigma_{\text {side plate }} \geq 7.5 \mathrm{MPa}, \sigma_{\text {rosta suspension }} \geq 4.3 \mathrm{MPa}, \\
\sigma_{\text {back plate }} \geq 15.4 \mathrm{MPa} \text { and } \sigma_{\text {screen deck frame }} \geq 15.3 \mathrm{MPa} \text { when RVS machine is used for } \\
\text { screening iron ore particles }\end{array}$ & $\begin{array}{l}\text { Heat stroke warning-RVS subsystems are in } \\
\text { faulty conditions }\end{array}$ \\
\hline $\begin{array}{l}\sigma_{\text {torsion bar }}<20.6 \mathrm{MPa}, \sigma_{\text {side plate }}<7.4 \mathrm{MPa}, \sigma_{\text {rosta suspension }}<4.2 \mathrm{MPa} \\
\sigma_{\text {back plate }}<16.8 \mathrm{MPa} \text { and } \sigma_{\text {screen deck frame }}<12.7 \mathrm{MPa} \text { when RVS machine is used for } \\
\text { screening coal particles }\end{array}$ & $\begin{array}{l}\text { No warning-RVS subsystems are in healthy } \\
\text { conditions }\end{array}$ \\
\hline $\begin{array}{l}\sigma_{\text {torsion bar }} \geq 20.6 \mathrm{MPa}, \sigma_{\text {side plate }} \geq 7.4 \mathrm{MPa}, \sigma_{\text {rosta suspension }} \geq 4.2 \mathrm{MPa}, \\
\sigma_{\text {back plate }} \geq 16.8 \mathrm{MPa} \text { and } \sigma_{\text {screen deck frame }} \geq 12.7 \mathrm{MPa} \text { when RVS machine is used for } \\
\text { screening coal particles }\end{array}$ & $\begin{array}{l}\text { Heat stroke warning-RVS subsystems are in } \\
\text { faulty conditions }\end{array}$ \\
\hline Vibration speed of the RVS machine $<0.283 \mathrm{~m} / \mathrm{s}$ & $\begin{array}{l}\text { Freeze warning-RVS machine is under- } \\
\text { functioning }\end{array}$ \\
\hline Vibration speed of the RVS machine $=0.283 \mathrm{~m} / \mathrm{s}$ & $\begin{array}{l}\text { No warning-RVS machine is functioning at } \\
\text { normal operating conditions }\end{array}$ \\
\hline Vibration speed of the RVS machine $>0.283 \mathrm{~m} / \mathrm{s}$ & $\begin{array}{l}\text { Heat stroke warning-RVS machine is } \\
\text { functioning abnormally }\end{array}$ \\
\hline Outward temperature of the RVS machine $\leq 80{ }^{\circ} \mathrm{C}$ & $\begin{array}{l}\text { No warning-RVS machine is functioning at } \\
\text { normal operating conditions }\end{array}$ \\
\hline Outward temperature of the RVS machine $\geq 80{ }^{\circ} \mathrm{C}$ & $\begin{array}{l}\text { Heat stroke warning-RVS machine is } \\
\text { functioning abnormally }\end{array}$ \\
\hline
\end{tabular}

Fig. 5 User interface of the host computer of the national instrument real-time monitoring system

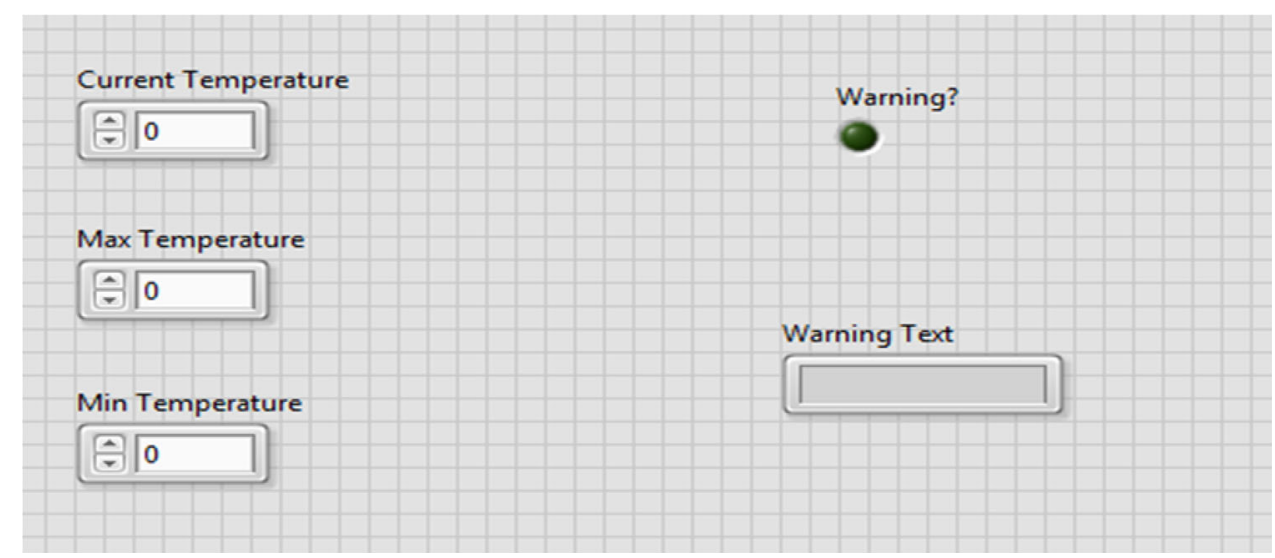

x. Connect the thermocouple to a port or channel, where temperature measurement will be taken on or around the vibrating motor powering the RVS machine.

xi. Connect the cables of the thermocouple to the data acquisition module of the real-time monitoring system.

xii. Configure the module to synchronize with the LABVIEW code.

xiii. Run the VI front panel by pressing the run button in order to ascertain the real-time temperature condition of the vibrating motor.

\section{RVS machine prognosis system model}

The reliability model used for predicting when each subsystem of the RVS machine will fail is modelled using the Markov algorithm. In light of this, a reliability and functional transition diagram used to model the RVS machine subsystems prognosis algorithms is depicted in Fig. 5. The assumptions used for this model are as follows:

a. Failure rates and repair rates of all the subsystems of the RVS machine vary from one particular period to another. 


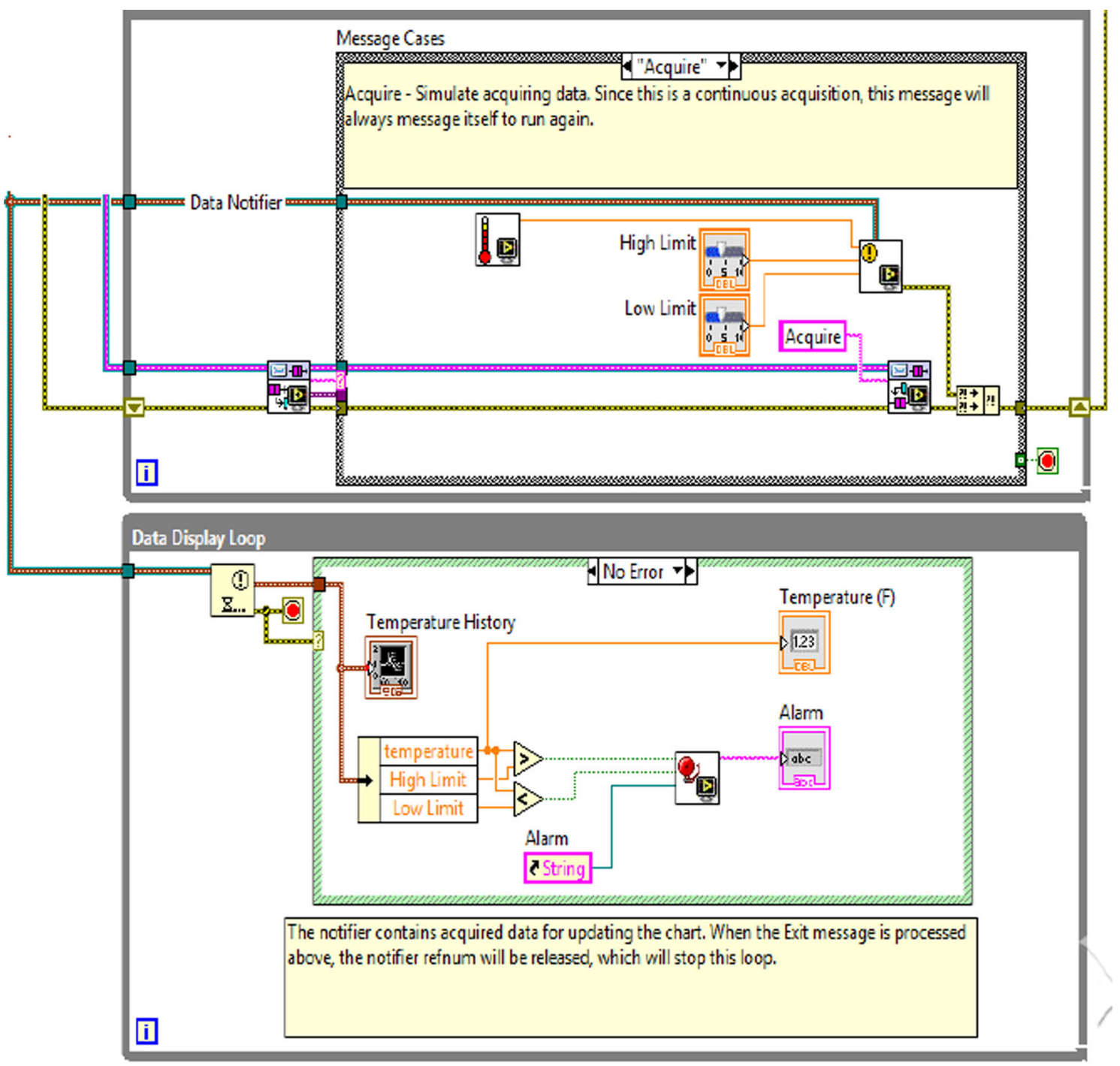

Fig. 6 Block diagram for the vibrating motor temperature measurement and warning system

b. The time between failure (TBF) and time to repair (TTR) data for RVS machine subsystems when utilized in the mining industries are expected to be exponentially distributed.

c. The probability that more than one subsystem of the RVS machine will breakdown is equal to zero.

d. The different subsystems of the RVS machine return back to their functional state when they are repaired and these subsystems are only repaired when any of them fails.

e. RVS machine subsystems are expected to exhibit only operating and non-operating states.

f. The algebraic sum of the operating and non-operating transition states of each RVS machine subsystem is equal to zero. g. The probabilities associated with the operating and non-operating transition states of each RVS machine subsystem are constant over a particular period of time.

Notations used for RVS machine prognostic model formulation are:

$\lambda_{i}$ is the failure rate of the reconfigurable vibrating screen subsystems $(i=1,2, \ldots 0.8)$.

$\mu_{i}$ is the repair rate of the reconfigurable vibrating screen subsystems.

$\mu_{s}=$ repair rate of the RVS machine.

FinalMTBF $=$ mean time between failures for final period of investigation.

InitialMTBF $=$ mean time between failures for the first period of investigation. 
$L_{\mathrm{used}}=$ used life of the RVS machine.

$L_{\text {r.v.s }}=$ life span or shelf life of the RVS machine.

$L_{\text {remain }}=$ remaining effective useful life of the RVS machine.

$M_{i}(t)=$ predicted maintainability of the RVS machine subsystems.

$M_{\text {r.v.s }}(t)=$ predicted maintainability of the RVS machine.

$\mathrm{MTBF}=$ mean time between failures. $\mathrm{MTBF}_{\text {r.v.s }}=$ mean time between failures of the RVS machine.

MTTR = mean time to repair for each of the RVS machine subsystems.

$n$ is the number of subsystems that ensures the proper functioning of the RVS machine.

$P K_{0}(t)$, represents the probability that the reconfigurable vibrating screen is in the 'operating state' $\left(S_{0}\right)$ at time $t$.

$P K_{i}(t)$, represents the probability that the reconfigurable vibrating screen subsystems are in the non-operating $\left(S_{i}\right)$ state at time $t .(=1,2, \ldots 6)$.

$R_{i}(t)=$ predicted reliability of the RVS machine subsystems.

$R_{\text {r.v.s }}(t)=$ predicted reliability of the RVS machine.

$\mathrm{TBF}_{1}, \mathrm{TBF}_{2}, \mathrm{TBF}_{3}, \mathrm{TBF}_{4}, \ldots, \mathrm{TBF}_{n}=$ time between failures for each of the RVS machine subsystems.

$\mathrm{TTR}_{1}, \mathrm{TTR}_{2}, \mathrm{TTR}_{3}, \mathrm{TTR}_{4}, \ldots, \mathrm{TTR}_{n}=$ time to repair each of the RVS machine subsystems.

\section{Model formulation}

From the transition diagram presented in Fig. 7, the Markov's equations can be derived.

The probability that the machine is in the operating state after time interval $\mathrm{d} t$ i.e. at time $(t+\mathrm{d} t)$ is given by:

$P K_{0}(t+\mathrm{d} t)$

$=[($ probability of being in operating state at time $\mathrm{t})$

AND (probability of not failing between $(t+\mathrm{d} t))$ ]

$+[$ (probability of being in failed states at time $t)$

AND (probability of being repaired betweentand $(t+\mathrm{d} t))$ ]

Probabilities of failure between $t$ and $\mathrm{d} t$ are $\lambda_{i} \mathrm{~d} t$ and the probabilities of not failing are $\left(1-\lambda_{i} \mathrm{~d} t\right)$.

Similarly, the probabilities of repair are $\mu_{i} \mathrm{~d} t$. Using the addition and multiplication rule for probabilities gives the equation:

$P K_{0}(t+\mathrm{d} t)=P K_{0}(t)\left[\sum\left(1-\lambda_{i} \mathrm{~d} t\right)\right]+\sum \mu_{i} \mathrm{~d} t P K_{i}(t)$

Simplifying Eq. (2) further gives Eqs. (3) and (4)

$$
\begin{aligned}
P K_{0}(t+\mathrm{d} t)-P K_{0}(t)= & \left\{P K_{0}(t)\left[\sum\left(1-\lambda_{i} \mathrm{~d} t\right)\right]\right. \\
& \left.+\sum \mu_{i} \mathrm{~d} t P K_{i}(t)\right\}-P K_{0}(t)
\end{aligned}
$$

Fig. 7 RVS machine functional transition tree diagram

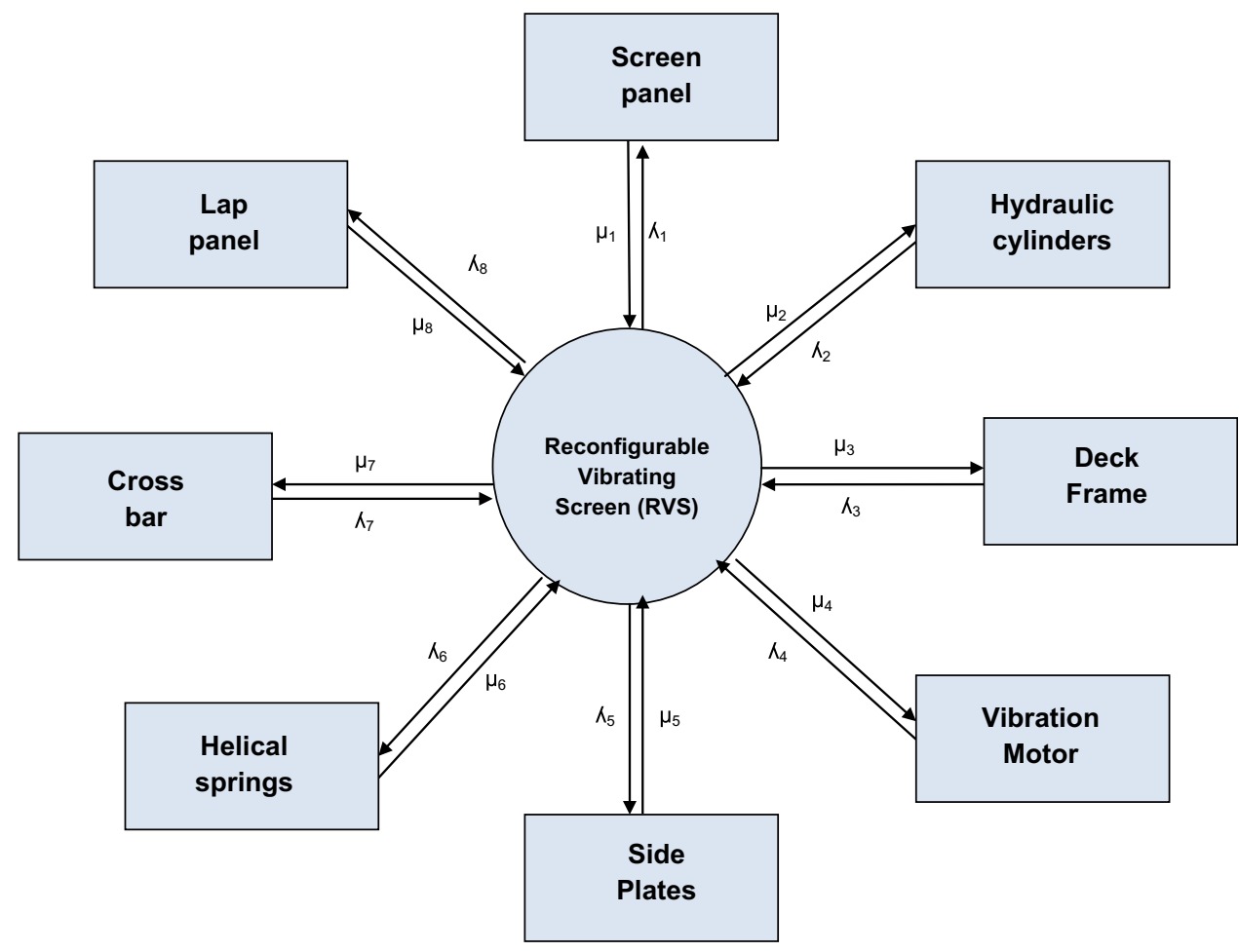




$$
\begin{aligned}
P K_{0}(t+\mathrm{d} t)-P M_{0}(t)= & \sum\left(-\lambda_{i} \mathrm{~d} t\right) P K_{0}(t) \\
& +\sum \mu_{i} \mathrm{~d} t P K_{i}(t)
\end{aligned}
$$

$\frac{P K_{0}(t+\mathrm{d} t)-P K_{0}(t)}{\mathrm{d} t}=\sum\left(-\lambda_{i}\right) P K_{0}(t)+\sum\left(\mu_{i}\right) P K_{i}(t)$ Asd $t \rightarrow 0$

$\frac{\mathrm{d} P K_{0}(t)}{\mathrm{d} t}=-P K_{0}(t) \sum \lambda_{i}+\sum\left(\mu_{i}\right) P K_{i}(t)$

$\frac{\mathrm{d} P K_{0}(t)}{\mathrm{d} t}=\sum\left(\mu_{i}\right) P K_{i}(t)-P K_{0}(t) \sum \lambda_{i}$

$\therefore P K_{0}(t)=P_{0} ; P K_{i}(t)=P_{i}$

Equating first order derivative of Eq. (3) to zero for a steady state, i.e. $\left(\frac{\mathrm{d} P K_{0}(t)}{\mathrm{d} t}=0\right)$, the Eq. (4) becomes Eq. (5) as expressed below:

$0=\sum \mu_{i} P_{i}-P_{0} \sum \lambda_{i}$

$\sum \mu_{i} P_{i}=P_{0} \sum \lambda_{i}$

$P_{i}=\frac{P_{0} \sum \lambda_{i}}{\sum \mu_{i}}$

i.e. $P_{1}=\frac{P_{0} \lambda_{1}}{\mu_{1}}, P_{2}=\frac{P_{0} \lambda_{2}}{\mu_{2}} \cdots P_{n}=\frac{p_{0} \lambda_{i}}{\mu_{i}}$

Recall that:

$P_{0}+P_{1}+P_{2}+\cdots P_{n}=1$

Substituting the value of $P_{1}, P_{2} \cdots P_{n}$ into Eq. (6), then the steady state of any machine $\left(P_{0}\right)$ is found to be:

$P_{0}=\left(\frac{1}{1+\sum \frac{\lambda_{i}}{\mu_{i}}}\right) \times 100 \%=\left(\frac{1}{1+D}\right) \times 100 \%$

where, $D=\sum \frac{\lambda_{i}}{\mu_{i}}$.

While the steady state availabilities of each of the RVS machine subsystems are depicted in Eq. (8).

$P_{1}=\frac{\lambda_{1}}{\mu_{1}}\left(\frac{1}{1+D}\right)$

$\left.P_{2}=\frac{\lambda_{2}}{\mu_{2}}\left(\frac{1}{1+D}\right)\right\}$

$P_{n}=\frac{\lambda_{n}}{\mu_{n}}\left(\frac{1}{1+D}\right)$

Therefore, the reliability of RVS machine $\left(R_{\text {r.v.s }}(t)\right)$ and each of its subsystems $\left(R_{i}(t)\right)$ can be obtained in real-time using Eqs. (9) and (10) while the maintainability of the RVS machine $\left(M_{\text {r.v.s }}(t)\right)$ and each of the subsystem of the RVS machine $\left(M_{i}(t)\right)$ can be determined using Eqs. (11) and (12).

$R_{\text {r.v.s }}(t)=\mathrm{e}^{-\sum \lambda_{i} t} \times 100 \%$

where $\sum \lambda_{i}=\lambda_{1}+\lambda_{2}+\lambda_{3}+\lambda_{4}+\lambda_{5}+\cdots+\lambda_{n}$.
$R_{i}(t)=\mathrm{e}^{-\lambda_{i} t} \times 100 \%$

$M_{\text {r.v.s }}(t)=\left(1-\mathrm{e}^{-\mu_{s} t}\right) \times 100 \%$

where, $\mu_{s}=\frac{1}{\mathrm{MTBF}_{\text {r.v.s }} \times D}$ and $\mathrm{MTBF}_{\text {r.v.s }}=\frac{1}{\sum \lambda_{i}}$

$M_{i}(t)=\left(1-\mathrm{e}^{-\mu_{i} t}\right)$

Equations (7)-(12) depict the steady state availability or functionality, reliability and maintainability of the RVS machine and each of its subsystems which can be obtained by assessing the failure rate and repair rate of each of the subsystems of the RVS machine over a certain period of usage of this machine. The failure rate and repair rate is calculated via Eqs. (13) and (14) using RVS machine subsystems historical failure dates and repair rates accessed from the database failure records or kit of the machine diagnosing system.

$\lambda_{i}=\frac{1}{\mathrm{MTBF}}$

where, $\mathrm{MTBF}=\frac{\mathrm{TBF}_{1}+\mathrm{TBF}_{2}+\mathrm{TBF}_{3}+\cdots+\mathrm{TBF}_{n}}{n}$

$\mu_{i}=\frac{1}{\mathrm{MTTR}}$

where, MTTR $=\frac{\mathrm{TTR}_{1}+\mathrm{TTR}_{2}+\mathrm{TTR}_{3}+\cdots+\mathrm{TTR}_{n}}{n}$.

Also, the remaining effective useful life of the RVS machine is determined using the steady state availability of this machine, and its corresponding value is obtained using Eq. (15). The Reconfigurable vibrating screen machine reliability decline growth rate (RVSMRDGR), which indicates the effectiveness of the maintenance strategies used in maintaining the RVS machine, can be calculated using Eq. (16).

$L_{\text {remain }}=P_{0} \times\left(L_{\text {r.v.s }}-L_{\text {used }}\right)$

RVSMRDGR $=\frac{\text { InitialMTBF }}{\text { FinalMTBF }}$

\section{RVS machine e-maintenance tools}

The predictive algorithms discussed in the previous section of this paper could be embedded using Information and communication and technology (ICT) tools in order to enable the real-time RVS machine subsystems' performance prediction as well as enable the extrapolation of RVS machine subsystems real-time degradation and wear rates. The predicted RVS machine algorithms depicted in Eqs. (8)-(15) can be coded and embedded to develop an e-prognosis system for this machine using ICT tools and accessories such as PHP (Hypertext Pre-processor), JavaScript, Google graph, application programming interface (API), jQuery, MySQL database and canvg-JavaScript SVG parser and renderer on canvas. The function of these 
ICT tools in developing the RVS machine e-prognostic system is highlighted as follows:

1. PHP - the server side scripting programming language that is used for interfacing the RVS machine predictive algorithm codes with the internet services in order to access other e-accessories used for analysing and interpreting the offline RVS machine performance data.

2. JavaScript - the client side scripting programming language that is used for coding the RVS machine predictive algorithms.

3. Google Graph API-this is used for plotting the reliability and maintainability graphs of the RVS machine and its subsystems in real-time.

4. jQuery - this tool reduces the complexity of code in JavaScript.

5. MySQL database-this tool is used for saving the results obtained from the RVS machine performance data processing.

6. canvg-Javascript SVG parser and renderer on canvas: this tool is used for saving the reliability and maintainability graphs of the RVS machine and its subsystems.

\section{RVS machine dynamic maintenance model}

Another maintenance strategy required to ensure optimal use of the RVS machine despite odd conditions such as unforeseen machine breakdown and repair processes as well as fluctuating and sporadic customer demands that could emanate during RVS machine utilization in the mining industry is the dynamic maintenance system. The dynamic maintenance strategy in this context, involves geometrically transforming or switching the RVS machine from one configuration to another configuration feasible within the RVS machine structure in order to mark-up the production loss that could emanate from the RVS machine breakdown and repair processes or increase the screening productivity rates of the machine as a yardstick to expedite production runs in meeting sporadic customer demands. The dynamic maintenance model formulations considered to keep the RVS machine at a new machine configuration in order to recover the production loss, that emanates when a machine break down and need to be repaired before the next cycle of usage is illustrated in Eqs. (17) and (18) while the dynamic maintenance formulations considered to keep the RVS machine at a new machine configuration in order to meet new customer demands are highlighted in Eqs. (19) and (20).

$P_{\text {gain }}=P_{n \text { thConf }}-P_{\text {initConf }}$ where, $n$ is the order of configuration (i.e. between 2 and 5) that the maintenance manager of the machine can reconfigure the machine to. $P_{n \text { thConf }}=$ productivity rate of the RVS machine at $n$th configuration per hour $P_{\text {initConf }}=-$ productivity rate of the RVS machine at the initial configuration per hour $P_{\text {gain }}=$ productivity gain or surplus due to RVS machine reconfiguration per hour

$$
\begin{aligned}
& R_{t_{1}}=\frac{\text { Total production loss during a certain period }}{P_{\text {gain }}} \\
& P_{\text {expected-hike }}=P_{\text {newdemand }}-P_{\text {initialdemand }}
\end{aligned}
$$

where, $P_{\text {expected-hike }}=$ additional or supplemental volume of mineral concentrates required to be produced in meeting new customers demand.Therefore,

$R_{t_{2}}=\frac{P_{\text {expected-hike }}}{P_{\text {gain }}}$

In light of this, it can be affirmed that the time required to keep the RVS machine at a new machine configuration in order to recover the production loss $\left(R_{t_{1}}\right)$ can be obtained using Eq. (18) while the time required to keep the RVS machine at a new machine configuration in order to meet the new customer's demand $\left(R_{t_{2}}\right)$ can be obtained using Eq. (20). In light of these discussions, holistic and systematic development and implementation of these diagnostic, prognostic, dynamic and e-driven maintenance strategies for RVS machine maintenance processes and operations in mining industries, will reduce drastically to the barest minimum, the downtime experienced by this machine, ensure Just-In-Time (JIT) maintenance of this machine and ensure lean production of mineral concentrates demanded by the customers in a cost-effective manner.

\section{Case study I: RVS machine diagnosis system model testing}

The state or current functional condition of the vibrating motor powering the RVS machine can be obtained by comparing and assessing the critical or maximum temperature of the vibrating motor as highlighted in the RVS machine rule-based condition monitoring algorithms, depicted in Table 1 with the current functional temperature at which the vibrating motor is vibrating the RVS machine during mineral particle beneficiation. As illustrated in Fig. 6, if the outward temperature measurement of the vibrating motor, obtained by a thermocouple fitted to a port around the vibrating motor is $29.9375{ }^{\circ} \mathrm{C}$ and the maximum critical temperature before vibrating motor can fail (which could results in bearing and weight failures of the vibrating motor) is $80{ }^{\circ} \mathrm{C}$, therefore it could be ascertained through the sequential processing of the codes depicted in 


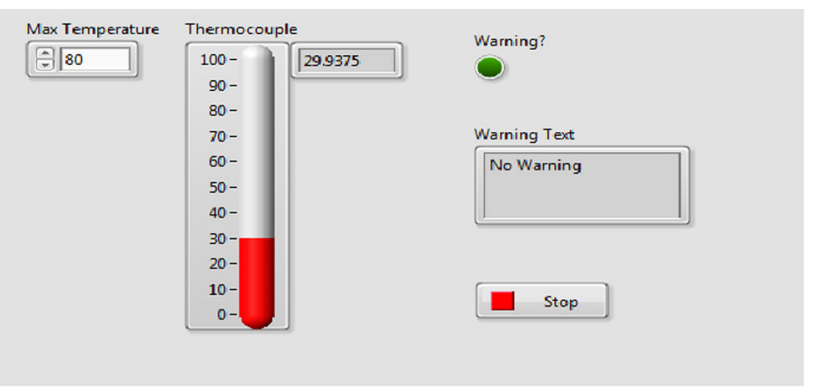

Fig. 8 A user interface reporting the current measurement and functional condition of the vibrating motor powering the RVS machine

Fig. 8 that the vibrating motor is in a healthy condition. However, if the outward temperature obtained from the thermocouple fitted to a port around a vibrating motor is $>80{ }^{\circ} \mathrm{C}$, it could be ascertained through sequential processing of the codes depicted in Fig. 8 that the vibrating motor is in a faulty or failing condition.

\section{Case study II: RVS machine prognosis system model testing}

To test the RVS machine prognosis model, historical data of the failure and repair records of the vibrating motor powering a conventional vibrating screen for the past 5 years in mining company XYZ; obtained from Makinde (2014) was used (Table 2). The conventional vibrating screen has a similar functional mechanism and subcomponents as the RVS machine.Using the information highlighted in Table 2, the key prognosis metrics required to make decision on when to repair or replace the vibrating motor was determined. From Table 2, the time between failures (TBF) for the vibrating motor are calculated as follows:

Table 2 Failure and repair history of vibrating motor used in powering a conventional vibrating screen in mining company $\mathrm{XYZ}$

\begin{tabular}{lc}
\hline Date of failure & Repair time (h) \\
\hline 28:02:2008 & 4.00 \\
19:03:2009 & 6.67 \\
27:03:2009 & 9.00 \\
15:04:2009 & 9.00 \\
02:08:2010 & 4.00 \\
20:04:2011 & 27.00 \\
02:04:2011 & 5.00 \\
30:11:2011 & 5.00 \\
\hline
\end{tabular}

$$
\begin{aligned}
\mathrm{TBF}_{1} & =9: 03: 2009-28: 02: 2008=1 \text { year } 19 \text { days } \\
& =9213 \mathrm{~h} \\
\mathrm{TBF}_{2} & =27: 03: 2009-19: 03: 2009=8 \text { days }=192 \mathrm{~h} \\
\mathrm{TBF}_{3} & =15: 04: 2009-27: 03: 2009=18 \text { days }=432 \mathrm{~h} \\
\mathrm{TBF}_{4} & =02: 08: 2010-15: 04: 2009 \\
& =1 \text { year3 months 17 days }=11334 \mathrm{~h} \\
\mathrm{TBF}_{5} & =20: 04: 2011-02: 08: 2010=8 \text { months } 18 \text { days } \\
& =6192 \mathrm{~h} \\
\mathrm{TBF}_{6} & =27: 04: 2011-20: 04: 2011=7 \text { days }=168 \mathrm{~h} \\
\mathrm{TBF}_{7} & =02: 06: 2011-20: 04: 2011=1 \text { month } 5 \text { days } \\
& =840 \mathrm{~h}
\end{aligned}
$$

Subsequently, the mean time between failures (MTBF) and the mean time to repair (MTTR) were calculated using the TBFs and the repair times illustrated in Table 2.

$$
\begin{aligned}
\text { MTBF } & =\frac{9213+192+432+11334+6192+168+840+13038}{8} \\
& =5176.13 \\
\text { MTTR } & =\frac{4+6.67+9+9+4+27+5+5+2}{9}=7.96
\end{aligned}
$$

The failure rate $(\alpha)$ and repair rate $(\theta)$ for the vibrating motor was obtained using Eqs. (13) and (14) as depicted below:

$\lambda=\frac{1}{5176.13}=0.00019$

$\mu=\frac{1}{7.96}=0.13$

The steady state availability of the vibrating motor, which pinpoints the level of usability and functionality of this vibrating screen subsystem is, determined using Eq. (7) as highlighted below:

$P_{0}=\left(\frac{1}{1+\sum \frac{\alpha_{i}}{\theta_{i}}}\right) \times 100 \%$

$P_{0}=\left(\frac{1}{1+\frac{0.00019}{013}}\right) \times 100 \%=99.85 \%$

Also, the predicted time to repair or replace the vibrating motor (depending on the severity of faults associated with the motor) can be calculated using Eq. (10) at a reliability value of $49 \%$ (i.e. the state at which the motor will be subjected to continuous and abrupt abnormal conditions):

$$
\begin{aligned}
& R_{i}(t)=\mathrm{e}^{-\alpha_{m} t} \times 100 \% \\
& 0.49=\mathrm{e}^{-0.00019 t}
\end{aligned}
$$

Therefore, $t$ (i.e. the predicted time to repair or replace the vibrating motor) is $3736.84 \mathrm{~h}$.

The degree or severity of maintenance required during the vibrating motor maintenance at the predicted time 
$3736.84 \mathrm{~h}$ can be ascertained using the maintainability parameter obtained from Eq. (12) as highlighted below:

$M_{i}(t)=\left(1-\mathrm{e}^{-\theta_{n} t}\right) \times 100 \%$

$M_{i}(t)=\left(1-\mathrm{e}^{-0.13(3736.84)}\right) \times 100 \%=100 \%$

This implies that there is $100 \%$ probability that the vibrating motor can be maintained at a reasonable or low cost and at the predicted time of failure, $3736.84 \mathrm{~h}$.

Furthermore, the remaining effective useful life of the vibrating motor, if the used life and the shelf life of this vibrating screen component are 3 and 5 years respectively is determined using Eq. (15) as highlighted below:

$L_{\text {remain }}=P_{0} \times\left(L_{\text {r.v.s }}-L_{\text {used }}\right)$

$L_{\text {remain }}=0.9985 \times(5-3)=1.997$ years.

\section{Case study III: RVS machine dynamic maintenance system model testing}

\section{Case study IIIA}

In order to recover the production loss that emanated during the maintenance of the vibrating motor on the 20th of April, 2011, as depicted in Table 2, then the RVS machine can be reconfigured from its 1 st configuration designed to operate at a dimension size and production capacity of $2500 \mathrm{~mm} \times 1500 \mathrm{~mm}$ and $68.8 \mathrm{tons} / \mathrm{h}$ respectively to its 5 th configuration designed to operate at a dimension size and production capacity of $4700 \mathrm{~mm} \times 2500 \mathrm{~mm}$ and 217.62 tons/h respectively. In view of this, using Eqs. (17) and (18) of the dynamic maintenance system model, the time required to set the configuration capacity of the RVS machine at its 5th configuration, in order to recover the production loss that emanated during the repair and maintenance of the vibrating screen motor on the 20th of April, 2011 is calculated as follows:

Production loss of the vibrating motor on the 20th of April; $2011=27 \mathrm{~h}$.

Hence, total production loss in tons for the month of April 2011

Total production loss $=27 \times 68.82$

Total production loss $=1858.14$ tons .

The productivity gain of the RVS machine $\left(P_{\text {gain }}\right)$ is given by:

$P_{\text {gain }}=P_{5 \text { thConf }}-P_{1 \mathrm{stConf}}$
$P_{\text {gain }}=217.62-68.82$

$P_{\text {gain }}=148.8$ tons

Therefore, the time required to keep the RVS machine at its 5 th configuration in order to mark-up or recover the production loss that emanated during the maintenance of the vibrating motor on the 20th of April in mining company $\mathrm{XYZ}$ is given by $R_{t_{1}}$ :

$R_{t_{1}}=\frac{\text { Total production loss during the month }}{P_{\text {gain }}}$

$R_{t_{1}}=\frac{1858.14 \text { tons }}{148.8 \text { tons } / \mathrm{h}}$

$R_{t_{1}}=12.4875 \mathrm{~h}$

$R_{t_{1}}=12 \mathrm{~h} 29 \mathrm{~min}$.

\section{Case study IIIB}

If the customers demand for limestone mineral concentrates in mining company XYZ increases from 49536-90,000 tons/month, owing to high needs for cement products for housing purposes; then to solve this problem, the mining company also needs to reconfigure their RVS machine from its 1 st configuration designed to operate at a dimension size and production capacity of $2500 \mathrm{~mm} \times 1500 \mathrm{~mm}$ and 68.8 tons/h respectively to its 5 th configuration designed to operate at a dimension size and production capacity of $4700 \mathrm{~mm} \times 2500 \mathrm{~mm}$ and 217.62 tons/h respectively in order to meet the new customers demand. In view of this, using Eqs. (17), (19) and (20) of the dynamic maintenance system model, the time required to set the configuration capacity of the RVS machine at its 5th configuration, in order to beneficiate 90,000 tons of limestone concentrates is calculated as follows:

The productivity gain expectant $\left(P_{\text {expected-hike }}\right)$ from the RVS machine is given by

$P_{\text {expected-hike }}=P_{\text {newdemand }}-P_{\text {initialdemand }}$

$P_{\text {expected-hike }}=90000-49536$

$P_{\text {expected-hike }}=40464$ tons

Therefore, the time required to keep the RVS machine at its 5 th configuration, in meeting the beneficiation of 90,000 tons of limestone concentrates in mining company $\mathrm{XYZ}$ is given by $R_{t_{2}}$ :

$R_{t_{2}}=\frac{P_{\text {expected-hike }}}{P_{\text {gain }}}$ 


$$
\begin{aligned}
& R_{t_{2}}=\frac{40464}{148.8} \\
& R_{t_{2}}=271.935 \mathrm{~h} \\
& R_{t_{2}}=11 \text { days } 7 \mathrm{~h} 56 \mathrm{~min} .
\end{aligned}
$$

\section{Conclusion}

A RVS machine has been vetted and proposed to the mining industries as the next line of beneficiation machine technology for screening mineral particles of varying sizes and volume sporadically demanded by the customers. However to ensure optimal functionality, usability, reliability and maintainability of this machine when utilized in the mining industry, a maintenance system model was extensively discussed in this paper and proposed to the potential users and the maintenance managers of this machine. This paper unveils the diagnostic algorithms using the national instrument (NI) real-time monitoring system as well as the RVS machine subsystems condition monitoring algorithms coded on the LABVIEW software tool of the NI system. Prognostic algorithms, which model and establish the maintenance parameters required in determining the reliability and maintainability of the RVS machine and its subsystems as well as ascertaining the steady state availability of the RVS machine and its remaining effective useful life was also unfolded. E-maintenance tools such as PHP, JavaScript, Google Graph API, jQuery, MySQL database and canvg-Javascript SVG parser and renderer on canvas, required to predict the functionality of the RVS machine subsystem in real-time and ascertain when to reconfigure the RVS machine in meeting new sporadic customer demands as well as recover the inevitable machine downtime that could emanate during RVS machine breakdown and repair processes was extensively discussed in this paper. Four different case studies were used to test this maintenance system model customized for maintaining the RVS machine. These revealed how the different components of the RVS machine can be diagnosed and prognosed and how the RVS machine can be dynamically maintained in recovering production loss that emanates during machine maintenance as well as meeting new customers demand. However, the experimentation of this maintenance system model (embedded with algorithms, e-maintenance tools) needs to be explored when the RVS machine is utilized in both surface and underground mines. The development of a predictive model capable of predicting the failure of two or more subsystems that occur simultaneously need to be explored in order to revoke the third limitation of the Markov model used by the RVS machine prognosis system. Further to this, the development of an expert system capable of establishing the causes of RVS machine subsystems failure should be explored, in order to complement the decisions of the RVS machine diagnosis system.

Acknowledgements Authors would like to appreciate the support from Department of Industrial Engineering, Tshwane University of Technology (TUT), South African National Research Foundation (NRF) and Manufacturing, Engineering and Related Services Sector Education and Training Authority (MERSETA) for their financial support in this research project.

Authors' contribution OM developed the maintenance model that was proposed for effective management of the RVS machine and compiled the first draft of the manuscript. BR conducted and documented the literature information that was used for this manuscript. KM, MKA and SPA reviewed and provided technical inputs that were used to enrich the manuscript. All the authors read and approved the final manuscript.

Open Access This article is distributed under the terms of the Creative Commons Attribution 4.0 International License (http://crea tivecommons.org/licenses/by/4.0/), which permits unrestricted use, distribution, and reproduction in any medium, provided you give appropriate credit to the original author(s) and the source, provide a link to the Creative Commons license, and indicate if changes were made.

\section{References}

Adeyeri MK, Kareem B (2012) Maintenance dynamics, tools for machines functionality in a competitive environment. Ind Eng Lett 2(7):12-19

Adeyeri MK, Kareem B, Ayodeji SP, Emovon I (2011) Dynamic maintenance strategy, the panacea to materials wastage from machinery. In: Proceedings of the World Congress on Engineering London, UK, vol 1, pp 1-5

Adeyeri MK, Mpofu K, Kareem B (2016) Development of hardware system using temperature and vibration maintenance models integration concepts for conventional machines monitoring: a case study. J Ind Eng Int 12(1):93-109

Adolfsson E, Dahlström T (2011) Efficiency in corrective maintenance a case study at SKF Gothenburg. Research Project, Department of Technology Management and Economics, Chalmers University of Technology, Sweden, pp 1-72

Afefy IH (2012) Maintenance planning based on computer-aided preventive maintenance policy. In: Proceedings of the International Multi Conference of Engineers and Computer Scientists, Hong Kong, vol 2, pp 1-6

Bouillaut L, François O, Leray P, Aknin P, Dubois S (2008) Dynamic Bayesian networks modelling maintenance strategies: prevention of broken rails. In: Proceedings of 8th world congress on railway research, Seoul, South Korea, pp 1-8

Carlo C, Andre L, Sylvie O, Henri P (2004) Detection of equipment aging and determination of the efficiency of a corrective measure. Reliab Eng Syst Saf 84(1):57-64

Cui L, Li H (2006) Opportunistic maintenance for multicomponent shock models. J Math Methods Op Res Eng 63(3):180-191

Gross P, Boulanger A, Arias M, Waltz D, Long PM, Lawson C, Anderson R, Koenig M, Mastrocinque M, Fairechio W, Johnson JA, Lee S, 
Doherty F, Kressner A (2005) Predicting electricity distribution feeder failures using machine learning susceptibility analysis. American Association for Artificial Intelligence, USA, pp 1-7

Haider A, Koronios A (2006) E-prognostics: a step towards e-maintenance of engineering assets. J Theor Appl Electron Commer Res 1(1):42-55

Hashemian HM (2011) Wireless sensors for predictive maintenance of rotating equipment in research reactors. Ann Nucl Energy 38(2-3):665-680

Ireland F, Dale BG (2001) A study of total productive maintenance implementation. J Qual Maint Eng 7(3):183-192

Iyoob I, Mohamed C, Richard C (2003) Analysis of equipment availability under varying corrective maintenance models. In: IEEE Annual Conference Proceedings, pp 1-5

Juricic D, Boskoski P, Petrovcic J, Musizza B (2013) Implementation of diagnostics, prognostics and e-maintenance support under variable operating conditions. In: International Conference on Maintenance Systems of the future, pp 1-16

Kenne JP, Boukas EK, Gharbi A (2003) Control of production and corrective maintenance rates in a multiple-machine, multiple-product manufacturing system. Int J Math Comput Model 38:351-365

Lee J, Ni J, Djurdjanovic D, Qiu H, Liao H (2006) Intelligent prognostics tools and e-maintenance. Comput Ind 57:476-489

Li Y, Chun L, Ching ANY (2005) An Agent-based platform for webenabled equipment predictive maintenance. In: Proceedings of the IEEE/WIC/ACM International Conference on Intelligent Agent Technology (IAT'05), pp 1-4

Makinde OA (2014) Functionality assessment of a reconfigurable vibrating screen. Master's Degree Thesis, Tshwane University of Technology, South Africa, pp 1-266

Makinde OA, Ramatsetse BI, Mpofu K (2015) Review of vibrating screen development trends: linking the past and the future in mining machinery industries. Int J Miner Process 145:17-22. doi:10.1016/j.minpro.2015.11.001

Makinde OA, Adeyeri MK, Mpofu K, Ramatsetse BI (2016a) e-Maintenance management system for optimal functionality of machines. In: Kadry S, El Hami A (eds) e-Systems for the 21st century: concept, developments, and applications. Apple Academic Press Publishers, Waretown, ISBN No 9781771882552, pp 1-944

Makinde OA, Mpofu K, Ramatsetse BI (2016b) Mining business optimization through a reconfigurable vibrating screen design. Afr J Sci Technol Innov Dev 8(1):88-96. doi:10.1080/20421338. 2015.1132549

Mohamed-Salah O, Daoud A, Alli G (1999) A simulation model for opportunistic maintenance strategies. IEEE Trans 1999:703-708

Mortazavi SM, Mohamadi M, Jouzdani J (2017) MTBF evaluation for 2-out-of-3 redundant repairable systems with common cause and cascade failures considering fuzzy rates for failures and repair: a case study of a centrifugal water pumping system. J Ind Eng Int 1-11. doi:10.1007/s40092-017-0226-6

Muller A, Marquez A, Lung B (2008) On the concept of e-maintenance: review and current research. Reliab Eng Syst Saf 93(8):1165-1187
Munirathinam S, Ramadoss B (2016) Predictive MODELS for equipment fault detection in the semiconductor manufacturing process. IACSIT Int J Eng Technol 8(4):273-285

Muruganantham VR, Kavi MS, Prabhu SR (2014) Analysis and implementation of total productive maintenance, kanban and JIT systems in small scale polymer industry. Int J Innov Res Sci Eng Technol 3(2):335-345

Osman HH, Hassan MA, Elhady NM, Elrasheed RM (2015) Computerized preventive maintenance management system (CPMMS) for haematology department equipment. Int J Comput Appl 109(16):9-12

Oyedepo SO, Fagbenle RO (2011) A study of implementation of preventive maintenance programme in nigeria power industryEgbin thermal power plant, case study. Energy Power Eng 3:207-220

Quintana R, Leung MT, Villalobos RJ, Graul M (2009) Corrective maintenance through dynamic work allocation and pre-emption: case study and application. Int J Prod Res 47(13):3539-3557. doi:10.1080/00207540701824225

Rajput HS, Jayaswal P (2012) A total productive maintenance (TPM) approach to improve overall equipment efficiency. Int J Mod Eng Res 2(6):4383-4386

Ramatsetse BI (2014) Development of a reconfigurable vibrating screen. Master's Dissertation, Tshwane University of Technology, Pretoria, South Africa

Salonen A, Deleryd M (2011) Cost of poor maintenance: a concept for maintenance performance improvement. J Qual Maint Eng 17(1):63-73

Samhouri MS, Al-Ghandoor A, Fouad RH, Alhaj-Ali SM (2011) An intelligent opportunistic maintenance (OM) system: a genetic algorithm approach. Jordan J Mech Ind Eng 3(4):246-251

Sheu DD, Kuo JY (2006) A model for preventive maintenance operations and forecasting. J Intell Manuf 17(4):441-451

Shrotri AP, Khandagale SB (2012) Design of a predictive maintenance program. Int J Eng Adv Technol 1(4):242

Singh R, Gohil AM, Shah DB, Desai S (2013) Analysis and implementation of total productive maintenance, kanban and JIT systems in small scale polymer industry. In: Chemical, Civil and Mechanical Engineering Tracks of 3rd Nirma University International Conference on Engineering (NUiCONE), Procedia Engineering, vol 51, pp 592-599

Tambe PP, Kulkarni MS (2013) An opportunistic maintenance decision of a multi-component system considering the effect of failures on quality. In: Proceedings of the World Congress on Engineering London, UK, vol 1, pp 1-6

Wan S, Gao J, Li D, Evans R (2014) Knowledge management for maintenance, repair and service of manufacturing system. In: The 12th International Conference on Manufacturing Research (ICMR) Southampton, UK. Pub Place: Southampton Solent University

Wang Y, Deng C, Wu J, Wang Y, Xiong Y (2014) A corrective maintenance scheme for engineering equipment. Eng Fail Anal $36: 269-283$ 